\title{
Written vs Spoken Narratives by Indonesian ESL Young Learners: A Case Study
}

\author{
Maria Fe Suganob Nicolau \& Katharina Endriati Sukamto \\ nicolau@binus.edu \& katharina.sukamto@atmajaya.ac.id \\ Binus School Simprug \& Graduate School of Applied Linguistics, Atma Jaya Catholic \\ University of Indonesia in Jakarta
}

\begin{abstract}
This study explores how Indonesian ESL Grade 2 elementary students studying in an international school in Jakarta produce written and spoken narratives. The stimulus material used to obtain the data was a four-panel comic strip with no written text. The findings revealed that both productions follow the basic global structure such as story elements, linearity of the storyline, and coherence. However, the written narratives contextually demonstrated formality while the spoken narratives displayed higher frequencies in using structure of discourse (e.g. hedges, contraction, repair and repetitions) and sentence complexity in T-units. Hedges were used as delaying tactics to allow more time for language processing. The use of contractions was due to the rapid production of language that constraints the ability of the students to produce syntactic richness. Repairs illustrated specificity of the chosen words, while repetition stemmed from the linguistic device like onomatopoeia that demonstrated the creative sides of the students to amplify their thoughts. Apparently, sentence complexity using the T-units demonstrated that the spoken narratives outnumbered the written mode. Nevertheless, it was apparent that the 2 T-units or 3 T-units followed a pattern (e.g. independent clause to independent clause with extension) which was a product of the participants' knowledge on spellings and construction of formal and complete sentences. These results may implicate that language educators need to heighten the learners' awareness of the unique linguistic features of each mode, to provide a clear understanding on how these modes work best in English language, and to attempt in establishing a balance in structure discourse and sentence complexity in T-units.
\end{abstract}

Keywords: ESL young learners, written and spoken narratives, pattern of differences

\section{Introduction}

Research on the differences between spoken and written language has been extensively carried out in different disciplines. In the cognitive context, the differences between the two modes may involve factors such as deliberateness and memory (Holowitz \& Newman, 1964), emotion and attitude (Leech, 1998), or time and space (Chafe, 1994; Biber, 1986). In the field of linguistics, the two modes are intrinsically distinct in terms of, among others, coherence (Bublitz, 1999; ACTFL, 1988; Tannen, 1984) and sentence complexity (Malvey, 2017; Greene \& Capella, 1986). The data for those studies are mainly obtained from L1 speakers. On the other hand, in the context of L2 learners, there has been a growing interest in the analysis of how these two modalities are analyzed such as syntactic complexity (Nicolau \& Sukamto, 2016; Lintunen \& Makila, 2014; Silva, Abchi \& Borzone, 2010); rigidity of grammar (Cao Thanh, 2015), and discourse structure (Sun \& Yang, 2011; Pu, 2006).

Regardless of the fact that the data were collected from L1 or L2, sentence complexities 
seem to be a more popular topic for discussion. For instance, Lintunen and Makila (2014) conducted a study based on the analysis of L2 English spoken and written productions of 18 L1 Finnish learners with the focus on syntactic complexity. The data consisted of written essays and transcribed spoken productions. In the written part, the students were asked to write an informal essay of 150-250 words while in the spoken part, they were shown a cartoon strip with six frames, and their task was to tell a story based on the cartoon. It revealed that the two modes have their own characteristics, and there are differences between native and non-native language use. Hesitations and pauses are not visible in the end result of the writing process, but they are characteristic of non-native spoken language use. Seemingly, written language was more complex than spoken language; however, the difference in the level of complexity was greater when a language segmentation unit such as T-unit analysis was used in segmenting the data.

Another study is by Silva, Abchi and Borzone (2010), who examined the differences between the speaking and writing skills of 1st and 2nd grade Spanish-speaking children. Children's writing abilities were evaluated with an oral/written retelling task. The authors considered length, T-Units, and syntactic complexity index (SCI) for the analysis, and a word spelling task to assess the basic skills of the children. The results showed differences between modalities in Text Length and T-unit, but not in SCI. The transcription processes did not affect the syntactic complexity of the written texts, even when they were shorter. Furthermore, the differences between modalities were less important in the 2nd grade. Also, the patterns of correlation of length and SCI with other tasks that evaluated transcription skills changed when the children got older. Feilke (1996 qtd in Abchi \& De Mier, 2017) revealed similar findings that young children ( 9 to 10 years old) mostly use coordinated sentences in written productions, but tend to integrate more information in subordinate clauses by the age of 14. Seemingly, teenagers and adults progressively use more nominalizations, which may be considered as a higher level of syntactic development. Taking into account specific measures to assess syntactic complexity (based on Hunt's works), previous studies of Spanish written productions have shown an increase in syntactic complexity associated with age and school level (Gutiérrez-Clellen \& Hofstetter, 1994).

On a more recent finding, Malvey (2017) conducted a study on complexity in written and spoken persuasive language tasks of ninth grade students in south-eastern United States. The students were asked to write a persuasive composition and speak about their opinion of high-school students having part-time jobs. The results demonstrated that the students used more complex syntax in their written persuasive language samples than in spoken language samples. On average, the participants made more utterance-level errors in the written texts. This study also shows that there was a significant negative relationship between errors at the word level that the students made and their scores on the writing tests. This means that the higher the students' writing score was, the lower number of wordlevel errors that the students made in the written persuasive task.

In Indonesia, a number of international schools are set-up in big cities like Jakarta. The majority of the students enrolled in these schools are locals whose first language is Indonesian. However, it can be observed that English becomes their lingua franca due to their exposure to the language. Such indication can be attributed to their environment, for instance, native English speaking teachers and the medium of instruction used in the both the school and family domains. As stated by Crystal (2003: 4), "language can be made a priority in a country's foreign language teaching, even though this language has no official status. This becomes the language which children are most likely to be taught when they arrive in school." In this case, students who are studying in bilingual or international schools are presumably better in their performance of English.

Apparently, at the school site where the data were obtained, some of the teachers commented that the young learners spoke 
spontaneously and fluently in English but some found it challenging to write their thoughts. To this effect, it is interesting to discover how these L2 young learners are responding to the two modes of language (written and spoken) in their early elementary years. This study aims to find out the research question: What are the patterns of similarities and differences between the written and spoken narratives?

It is noteworthy to mention that unlike some previous studies that used two different instruments to collect the written and spoken data (among others, Lintunen \& Makila, 2014; Cao Thanh, 2015; Sun \& Yang, 2011), in this study the authors preferred to use a single instrument to obtain the two sets of data. It is probably too early to mention that the different genres used in earlier studies might be considered as a contributing factor for the difference between the written and spoken outputs. Horowitz and Samuels (1987) claimed that while distinct patterns have emerged from these comparisons, the characterizations may partly be due to the genre differences because patterns of discourse such as rhetoric structures, attribution, adversative, covariance, and response, etc. do not work in the same way across readers of various age groups and grades and across text topics. Therefore, following Pu (2006), in his study we used a single instrument - in this case a series of pictures - for the two modes of language.

\section{Methodology}

This section involves a description of the participants and the research methodology that spells out the procedural method of the study.

\section{Participants}

The participants of the study were 77 Grade 2 students at BINUS School Simprug whose age level ranged between seven to eight years old when the data were collected in the first and second week of February 2017. The participants were all Indonesians who spoke Indonesian as their first language. However, in their daily activities, they often conversed in English both at school and at home. English became their most comfortable language due to the fact they attended an international school where almost all subject disciplines except for Indonesian and Chinese were taught in that language. This was also intensified by the composition of the teachers who were mostly native English speakers.

In referring to the participants in this study, the authors assigned a pseudonym to each student to safeguard their identity and privacy. For example, for the male students, we used Boy 1, Boy 2, and so on; and for the female students, Girl 1, Girl 2, and so on.

\section{Research Methodology}

The stimulus material was a four-panel comic strip with no written text (see Appendix) which was considered appropriate for the age and grade level of the students. This material was used to conduct both the written and spoken narratives of the students to analyze the difference between two modalities.

Firstly, the participants were asked to do the written narrative task. Before they started writing their narratives, an orientation was given to ensure that they understood the task given to them. After which, they were instructed to make their own storyline based on the comic strip with four frames with an emphasis that there was no right or wrong interpretation. This was to condition the mindset of the children that they could explore their sense of creativity in writing a narrative and that no pressure was put on them. Subsequently, after 10 minutes, 69 of the total participants (90\%) were done with their written tasks.

The spoken narrative task was conducted a week after the written one. This was to give space between the introductions of the two modes and to hypothesize that a leeway would not make a big difference between the written and spoken narratives. Like the written narratives, the students were instructed to tell something about the comic strips. This time, however, they only used the 
spoken modality wherein the data were recorded using an audio recorder.

In the attempt to examine the patterns of similarities and differences between written and spoken narratives, Pu's (2006) comparative discourse analysis and Hunt's (1970) T-units measurement were used as the framework of the study. Hunt (1970) underscored that a sentence has two (or more) T-units when independent clauses are conjoined (e.g. There was a woman next door, and she was a singer), but a single $\mathrm{T}$-unit when one or more clauses are embedded in an independent clause (e.g. There was a woman next door who was a singer). Table 1 presents the T-units to view the complexity of the sentence production (Hunt, 1970).

Table 1. T-units and their corresponding sentence samples

\begin{tabular}{|c|c|}
\hline T-unit & Sentence \\
\hline 1 T-unit (1 independent clause) & Ana ate the apple. \\
\hline 1 T-unit (1 independent clause with extension) & Ana ate the apple that fell from the tree. \\
\hline 1 T-unit (1 independent clause with a dependent clause) & Ana ate the apple after she found it. \\
\hline 2 T-units (2 independent clauses) & Ana ate the apple and she took a nap. \\
\hline
\end{tabular}

\section{Findings and Discussion}

Generally speaking, the students were able to produce comparable episodes in terms of story elements (e.g. characters, plot, and setting), linearity of the storyline and inference making. The overall structure of the two narratives is quite similar; however, there are identifiable differences observed between the two modalities. The remaining sections of the paper will focus on the emerging similarities and differences of both modalities in terms of their structural discourse and construction.

\section{Similarities between Written and Spoken Narratives}

All participants constructed the written and spoken narratives following the basic global structure of the story which is the beginning, middle, and end. The structure was made possible as each frame of the comic strips shows the picture clues. In terms of organization and coherence, the written and spoken narratives are strikingly similar because of the constraint of story frame, such as the speaker's/writer's expectations about how stories should be told and the fulfilment of the expectations (Tannen, 1993). Also, a written narrative usually follows a skeletal description of the fundamental events in their natural, logical and chronological order (Toolan, 1988; Yu, 2005).
In the same vein, although the participants were not able to exactly deduce the thoughts of the 'mother' (a character in the comic) as projected in the script, the participants stayed connected with the setting of the story (the school) due to the picture cues such as a backpack that the characters are carrying at their back. This suggests that the visual stimuli constructed a mental representation of what they perceived, and encoded it into a linguistically structured message. In addition, not all episodes were elaborately described in both modalities, yet the students could concentrate on the major events and focus less on the less significant actions and descriptions of the characters.

In relation to how the students introduced the narration of the events, they started with the phrase "once upon a time or one day". When a student was informally asked why she commenced the sentence in such a way, she stated "Usually, when I'm reading storybooks, they start with those lines. Teacher also mentioned that make believe story can start with once upon a time" (Girl 1). According to Holowitz and Newman (1964: 162 ), this utterance segment is marked as communicative signal since the sender signals that she/he is about to transmit an idea.

Consequently, the use of then and and are commonly practiced in order to connect one episode to the next. It can be observed 
that the organization of both written and spoken narratives displays somehow uniform construction. These are exhibited in the following table:

Table 2. The use of then and and at the start of the sentence

\begin{tabular}{|c|c|}
\hline Written & Spoken \\
\hline Then the kids arrived to school (Girl 26) & $\begin{array}{c}\text { Then they are really tired and sad. (Girl 4) } \\
\text { Then the mom was going to get something } \\
\text { Then they are in school now (Boy 4) }\end{array}$ \\
$\begin{array}{c}\text { And they were hearing some noise (Girl 3) } \\
\text { And they walked and walked (Boy 1) }\end{array}$ & $\begin{array}{c}\text { And walked until they are at school (Girl 35) } \\
\text { And the kids don't like to go to school they } \\
\text { like to play Ipad all the time (Boy 17) }\end{array}$ \\
\hline
\end{tabular}

Despite the identifiable similarities of the two modes, it is also interesting to explore the level of their differences which are discussed in the succeeding sub-topics.

\section{Differences between Written and Spoken Narratives}

The differences of the two modalities are focused on the structure of discourse (e.g. hedges, contraction, repair and repetition) and T-units. The discussion below exemplifies the analysis of the sub-topic.

\section{Hedges}

The apparent feature of hedges such as I think and maybe are observed in spoken narratives and not at all in the written ones. Observe the following:

(1) I think the mom told them to go to school. (Girl 6)

(2) I think the mom is saying goodbye to the kids. (Boy 2)

(3) I think there is something in the computer. (Boy 3)

(4) Maybe they are lazy and sad. (Girl 5)

(5) And maybe the said to go to school. (Boy 27)

The data shows that the students seem to suggest the absence of absoluteness or the varying amount of accuracy of their statements by using hedging devices and displaying uncertainty and reservation. In the case of Girl 6, she used hedges (e.g. I think) as a delaying tactic to think of the next words to utter in order to complete her statement. This implies that the student attempts on saving her face in case of any possible falsification of judgments. This solidifies Chafe and Nichols' (1986) claim that hedges are often limited only to expressions showing that "the match between a piece of knowledge and a category is less than perfect." In writing, the writer always has more time for language processing while in speaking, the speaker attempts to give spontaneous and on the spot spoken utterances which gives her/him the freedom to speak without looking back at the structure of grammar and spelling. Pu (2006) claims that writers usually plan a clause/sentence ahead before they write it down, and they have time to resolve uncertainly and avoid hesitation before producing a word or phrase.

\section{Contraction}

Unlike the written narratives, spoken narratives demonstrated a lot of contraction, such as the following:

(6) While they're...while they arrived at school, their mom was working (Girl 1)

(7) ... because it's very far and their mom always help them (Girl 6)

(8) They don't have a car so they want to walk to school. (Boy 2)

(9) The mom worked and they didn't tidy their room. (Boy 3)

The above data suggest that most of the students understood that they should employ more formality in their written narratives than the spoken ones. The instances of using contractions in the spoken mode were 
demonstrated since they spontaneously expressed their thoughts without being bothered by the formality of the sentence. Further, the need to produce language rapidly to narrate the story might constraint the ability of the students to produce syntactic richness. Thus, this current study reinforced the findings of Chafe and Danielwicz (1987: 9) that "if we put that difference aside, contractions can be regarded as further examples of innovative spoken vocabulary, innovations which the most formal kind of written language avoids altogether, but which more casual writing is more willing to accept." As also stated by $\mathrm{Pu}$ (2006: 46), "spoken narratives commonly used contractions, which is a feature much like the use of informal, colloquial vocabulary."

\section{Repairs and Repetition}

Repairs are evident in spoken narratives. The data revealed that 17 utterances contained repairs which are further categorized in two categories: lexical repair and syntactic repair. In lexical repair, the speaker changes from one lexical item to another. The examples can be seen below:

(10) The family... the kids have to go to school. (Girl 22)

(11) Then their mom is playing the computer... laptop. (Boy 34)
Examples (10) and (11) demonstrate that the students repaired the lexical terms (family to kids and computer to laptop) to illustrate specificity with the chosen word. This type of self-repair, according to Kormos (1999 \& 2000), is made to modify the information provided earlier by the speaker.

On the other hand, syntactic repair happens when the speaker changes the tense of the verb such as the following:

(12) Serah love... Serah loved to study. (Girl 43)

In this case, Girl 43 seemed to realize that she should have used the past form of the verb love, since she used past tense for the previous utterances: And they walked until they were in school. They studied. Serah love... Serah loved to study. As English is not the first language of the student, it seems that the student was able to apply the monitoring strategy (Krashen, 1982) in her L2 utterances.

The difference in discourse is further observed in repetition which gives away to both spoken and written narratives. Table 3 presents the occurrence of repetition in both modalities.

Table 3. Occurrence of repetition in written and spoken narratives

\begin{tabular}{|c|c|}
\hline Written & Spoken \\
\hline $\begin{array}{c}\text { At school they opened the door and they hear } \\
\text { tap tap (Girl 24) }\end{array}$ & They walk in the street very very long (Girl 17) \\
$\begin{array}{c}\text { The mommy is typing tap tap tap with her } \\
\text { computer (Boy 11) }\end{array}$ & $\begin{array}{c}\text { While they were walking and walking, they still felt lazy } \\
\text { to go school (Girl 26) }\end{array}$ \\
They were sad and they walk and walk and walk (Girl 40) \\
\hline
\end{tabular}

The occurrence of repetition in the written narratives looks interesting. The students used a linguistic device such as onomatopoeia (e.g. tap, tap, tap) to exemplify the sound produced by the laptop whereas in the spoken counterpart, they used only the clause (e.g. playing in the computer - Girl 24; worked in the computer - Boy 11). This implies that the students show their creative sides in producing colorful components of the vocabulary to amplify their thoughts. In fact, Menn and Vihman (2011) argued that onomatopoeia often constitute a considerable portion of the initial language development and a focus on this early vocabulary may explain some of the children's lexicon as they progress towards the adulthood.

In a different context, the spoken data as shown in Table 3 produced a different viewpoint. The students attempted to repeat a word to highlight its position in the narrative. For instance, "They walk in the street very very long" (Girl 17). The adverbial form very is 
repeated to suggest that the comic strip character has still a long way to travel. Interestingly, the message conveyed by the other students (Girl 26 and Girl 40) are identical, yet they presented it in a different writing structure. This assumption takes place since three out of the four panels of the comic strips show the same activity of the characters which is "walking". This informational salience in a narrative seems to create a connection which in some way assists the clarity of communication.

\section{T-units}

The syntactic complexity measure focuses on the production of complex sentences shown by the complexity of the T-units. Hunt (1970: 189) defines a T-unit as "the shortest unit into which a piece of discourse can be cut without leaving any sentence fragments as residue". Each T-unit contains one independent clause and its dependent clauses. Dependent clauses, which are connected to the independent clause via subordinate conjunctions (e.g. that, when, if, whether, though, although), function as noun clauses, adjective clauses, or adverb clauses. Even if two independent clauses are connected with a coordinating conjunction (e.g. and, but, or, nor), the total number of T-units is two, not one.

Graph 1. Overall Number of T-units

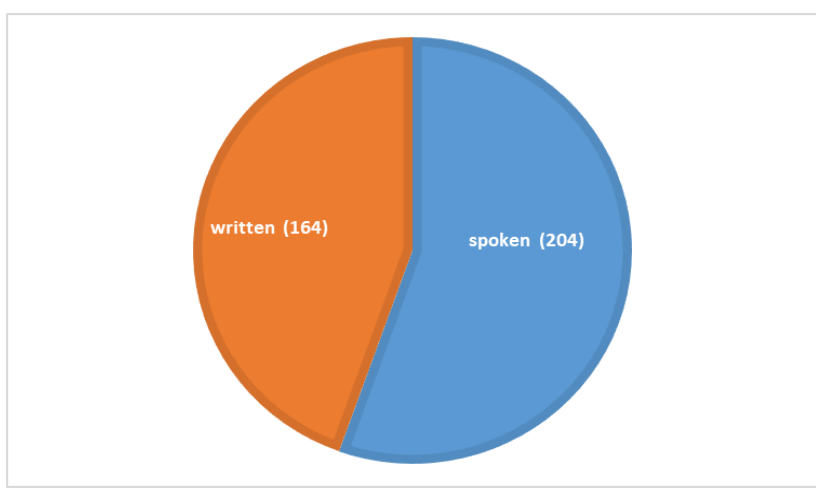

Graph 1 shows the comparison between the overall number of T-units of written and spoken narratives. Based on Lu's (2010) Tunit analyzer, this study reveals that the written narratives have $204 \mathrm{~T}$-units while the spoken narratives have $164 \mathrm{~T}$-units. This can be construed that the students are more comfortable in constructing complete sentences in their spoken narratives. This supports the statement of Biber (1986) that "linguistic differences between speaking and writing have been attributed to differing processing constraints and to differing situational characteristics" (23), which in the current finding is attributed to the age and grade level of the students as supported by (Abchi \& De Mier, 2017), limited knowledge of correct spelling (e.g. heer (hear), becuas (because), tierd (tired) and the construction of formal and complete sentences in the written form. In a different context, it can be noted that the spelling of words is incorrect; yet the students were observed to write the spelling that are phonologically the same as the linguistic term it refers to.

On the other hand, Graph 2 below displays the results of the sentence complexity of T-units between the written and spoken narratives of the students. 
Graph 2. Sentence Complexity in T-units

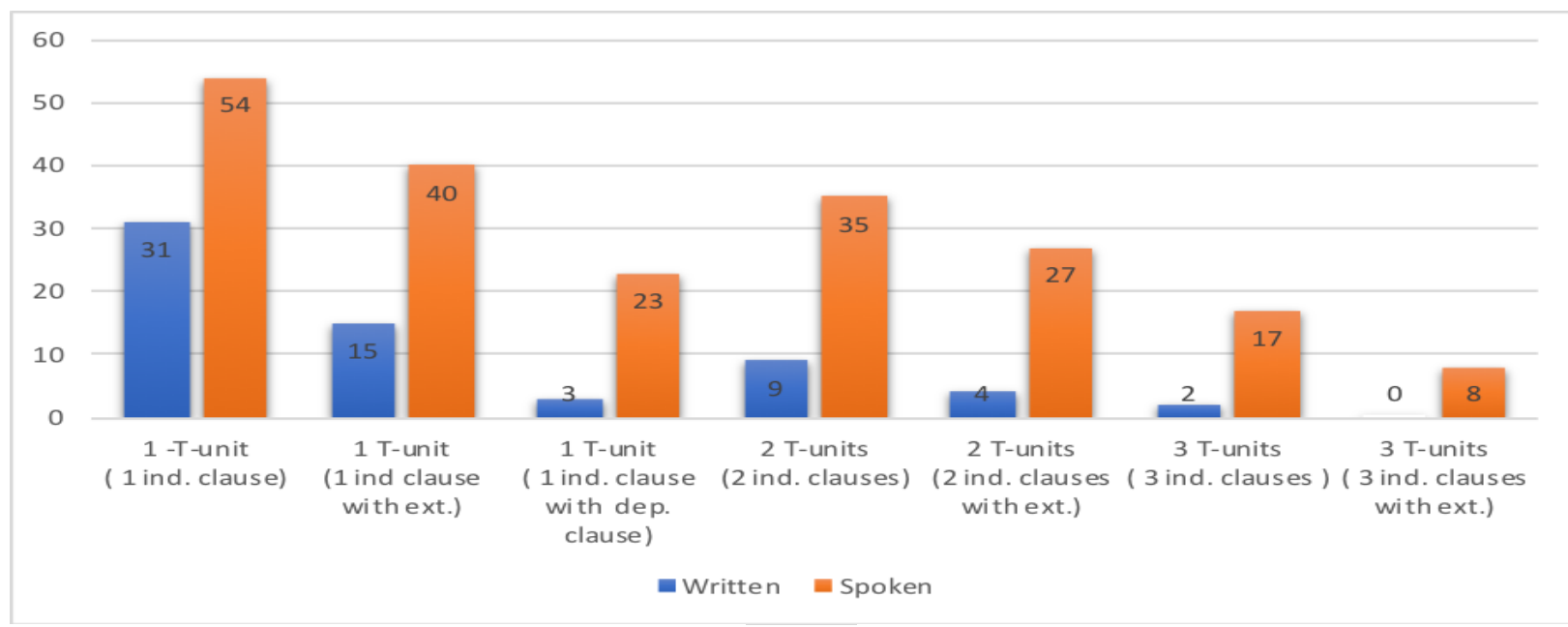

Graph 2 shows the comparison of the sentence complexity production of T-units between written and spoken narratives. Written narratives display from the highest to lowest rank: 1 T-unit (1 independent clause) with 31 occurrences, followed by 1 T-unit (1 independent clause with extension) (15), then by 2 T-units ( 2 independent clauses) (9), by 2 T-units (2 independent clauses with extension (4), by 1 T-unit (1 independent clause with a dependent clause) (3), and finally 3 T-units (3 independent clauses) (2).

On the other hand, the spoken narratives show that the highest rank is occupied by 1 T-unit (1 independent clause) with 51 occurrences, followed by 1 T-unit (1 independent clause with extension) (40), then by 2 T-units ( 2 independent clauses) (35), by 2 T-units (2 independent clauses with extension (27), by 1 T-unit (1 independent clause with a dependent clause) (23), by 3 T-units (3 independent clauses) (17), and finally 3 T-units (3 independent clauses with extension) (8).

The production of sentence complexity is much higher in spoken narratives than in written ones. It can be construed that the developmental learning stage of the students who are still in the process of learning and enhancing their formal sentence construction is a contributory factor. This finding has been supported by Abchi and De Mier (2017) and Gutiérrez-Clellen and Hofstetter (1994) who claimed that although this phenomenon appears simplistic, the syntactic level is still strongly correlated with school level and age. Cao Thanh (2015), on the other hand mentioned that spoken language often does not require strict rules, so it is less rigid and more flexible than the written language. Newman and Holowitz's (1964) findings though conducted decades ago still observably support the current study that the spoken expression produces a significantly greater number of word-token and more ideas of all kinds (e.g. main ideas, subordinate ideas, and ancillary ideas) in comparison to writing. The speaker's verbosity and prolixity to the extent of repetition cause the spoken language to become richer and fuller.

Interestingly, the data in graph 2 also reveals that whether the sentence is a $1 \mathrm{~T}$-unit or $2 \mathrm{~T}$-units or $3 \mathrm{~T}$-units, the sequence follows a pattern from independent clause (e.g. The boy and the girl are going to school) to independent clause with extension (e.g. They school is far from their house.). Nonetheless, Tunits (individual clauses with extensions) were only apparent in $2 \mathrm{~T}$-units and $3 \mathrm{~T}$-units.

On a separate note, the most common coordinating conjunction and is used to link 2 T-units and 3 T-units to demonstrate the complexity of sentences. The written narratives reveal that and connects the two independent clauses which have the same subject. This would mean the anaphora (e.g. they) refers back to the same entity in this 
case the 'kids'. In contrast, the spoken narratives show a different pattern. And is shown to link two independent clauses with two different subjects (e.g. kids and mom) and two different activities. Pragmatically speaking, the speakers (students) seem to establish a common understanding of the topic with the listener; thus maintaining the spontaneity of the interaction. The samples of sentences are presented below:

Table 4. And as a coordinating conjunction

\begin{tabular}{|c|c|}
\hline Written Narratives & Spoken Narratives \\
\hline $\begin{array}{c}\text { The kids are walking to school and they are not } \\
\text { happy. (Girl 5) } \\
\begin{array}{c}\text { The kids are walking and they don't have a car. } \\
\text { (Boy 14) }\end{array}\end{array}$ & $\begin{array}{c}\text { The two kids are going to school and the mom is } \\
\text { saying good bye. (Boy 20) }\end{array}$ \\
$\begin{array}{c}\text { The mom is working and they didn't tidy the room. } \\
\text { (Girl 25) }\end{array}$ \\
\hline
\end{tabular}

Further, the coordinating conjunction and does not only function as a connector between independent clause and dependent clause but it also signals as a commencing word to a new episode as seen in Table 5 . (Note: Narratives' spelling and grammar are not edited based on natural data provided by Boy 3.)

Table 5. Written and spoken narrative data using and (Boy 3)

\begin{tabular}{|c|c|}
\hline Written & Spoken \\
\hline $\begin{array}{c}\text { The children are going to school by them selves. } \\
\text { The children are going to school with walking. } \\
\text { And they are still walking. }\end{array}$ & $\begin{array}{c}\text { The childrens are ready to go to school. } \\
\text { And the mother say good bye to the childrens. } \\
\text { The childrens say good bye to the mother. } \\
\text { And the children walked away far to the school. } \\
\text { And then the children are near the school. } \\
\text { The children are in the school and the teacher } \\
\text { typing the computer for the childrens. }\end{array}$ \\
\hline
\end{tabular}

The initial position of the conjunction and in the two narrative modes indicates the sequential order of the events. The presence of and also separates one sentence to the other which allows the students to construct simple complete thoughts. Likewise, some students pause for a few seconds and repetitively use the word and (e.g. and, and they walk, and till they'll reach their house Boy 5), in their spoken narratives to indicate that they are thinking for the lexical term or the supporting ideas to utter. This was also supported by the length of their utterances in comparison to the written narratives. In fact, 51 similar instances were observed in both modalities. Accordingly, spoken language is normally produced in small spurts (Gee, 2011; Chafe, 1994). These spurts or chunks of speech are produced between boundaries; one chunk is separated from another by a pause. Each chunk consists of situational linguistic material which reflects the speaker's thought(s) at the time of utterance (Sukamto \& Yanti, 2013). Chafe and Danielewicz (1987) also mentioned that the speakers try to avoid complex interclausal relations because an elaborated syntax evidently requires more processing effort than speakers can ordinarily devote to it. It might be too early to assume that the linguistic repertoire of the seven to eightyear-old students in terms of conjunction is focused on the most common coordinating connectors such as and and but. Statistically speaking during the summer of 2012 review, the Corpus of Contemporary American English indicated 10,741,073 used of and within its expansive collection. This amounts to roughly 2.4 percent of all words, making and the third most common word in the English language (Kokemuller, 2017). 


\section{Conclusion}

Both modalities follow the basic global structure in terms of story elements (e.g. characters, plot, and setting), linearity of the storyline, inference making and coherence because of the limitation of story frames. The students stayed connected with the setting of the story due to the visual stimuli that construct a mental representation of what they perceived, and encoded them into a linguistically structured message. Further, the apparent use of the phrase once upon a time or one day indicated the start of the sentences while the use of then and and signalled the next episode of the narration. This solidifies the argument of $\mathrm{Pu}$ (2006) that despite the differences of the two modes, they still follow the universal characteristics of narrative discourse and human cognition.

Although the written narratives were observed to demonstrate formality in context, the spoken narratives displayed higher frequencies in using structure of discourse (e.g. hedges, contraction, repair and repetitions) and sentence complexity in Tunits. For instance, hedges functioned as delaying tactics of the students to think of the next words or clause to utter allowing more time for language processing. Likewise, the use of contractions was due to the rapid production of language to narrate the story that constraints the ability of the students to produce syntactic richness. Seemingly, repairs were also apparent to illustrate specificity of the chosen words (e.g.family to kids, computer to laptop) while repetition stemmed from the linguistic device such as the onomatopoeia (e.g. tap, tap, tap) that demonstrated the creative sides of the students in producing colorful components of the vocabulary to amplify their thoughts. In terms of sentence complexity using the T-units, it demonstrated that the spoken narratives outnumbered the written mode. It was also apparent that the 2 T-units or 3 T-units followed a pattern, that is, independent clause to independent clause with extension, which was a product of the participants' knowledge on spellings and construction of formal and complete sentences.
The findings suggest that despite the use of a single stimulus material to compare the written and spoken narratives, there are apparent intrinsic differences between the two modes. These results may hold some implications to the language teachers to heighten the learners' awareness of the unique linguistic features of each mode and to provide a clear understanding on how these modes work best especially in English language. Further, a longitudinal study is recommended to explore how the learners develop narrative structures of the two modes across different cultural backgrounds. As regards to the limitations of this study, future comparative studies among international schools with bigger scale of respondents are suggested to academically comprehend the learners' competence in both written and spoken language.

\section{References}

Abchi, V. S., \& De Mier, V. Syntactic complexity in narratives written by Spanish heritage speakers. Vigo International Journal of Applied Linguistics, 14, 2017: 125-148. doi:10.2307/34331.

American Council on the Teaching of Foreign Languages. ACTFL Japanese proficiency guidelines. Foreign language annals. 1, 1988: 589-603.

Biber, D. Spoken and written textual dimensions in English: Resolving the contradictory findings. Los Angeles: University of Southern California, 1986.

Bublitz, W. Introduction: views of coherence. In W. Bublitz, U. Lenk, and E. Ventola (eds.), Coherence in spoken and written discourse: how to create it and how to describe it: selected papers from the International Workshop on Coherence, Augsburg, 24-27 April 1997. Amsterdam: John Benjamins, 1999.

Cao Thanh, N. The differences between spoken and written grammar in English, in comparison with Vietnamese. $A$ tagmemic comparison of the structure of 
English and Vietnamese sentences, 11, 1971: 138-153. Retrieved from https://files.eric. ed.gov/ fulltext/ EJ1084418.pdf

Chafe, W. Discourse, consciousness and time: The flow and displacement of conscious experience in speaking and writing. Chicago: The University of Chicago Press, 1994.

Chafe, W., \& Danielwicz, J. Properties of spoken and written language (CSW-TR-5). Retrieved from Office of Educational Research and Improvement (ED), Washington, DC, 1987. website: https://files.eric.ed.gov/fulltext/ED28223 0 .pdf

Chafe, W., Nichols, J. Evidentiality: The linguistic coding of epistemology. Norwood, NJ: Ablex, 1986.

Crystal, D. English as a global language. Cambridge: Cambridge University Press, 2003.

Gee, J.P. An Introduction to Discourse Analysis: Theory and Method. 3rd Edition. New York: Routledge, 2011.

Greene, J.O. \& Cappella, J.N. Cognition and talk: The relationship of semantic units to temporal patterns of fluency in spontaneous speech. Language and Speech, 29, 1986: 141-157.

Gutierrez-Clellen, V. F., \& Hofstetter, R. Syntactic complexity in Spanish narratives. Journal of Speech Language and Hearing Research, 37(3), 1994: 645654. doi:10.1044/jshr.3703.645

Horowitz, M. W., \& Newman, J. B. Spoken and written expression: An experimental analysis. The Journal of Abnormal and Social Psychology, 68(6), 1964: 640-647.

Hunt, K. W. Recent measures in syntactic development. In C. J. Fillmore \& D. T. Langendoen (Eds.), Studies in linguistic semantics, 1970: 115-149. New York: Holt, Rinehart and Winston.

Kokemuller, N. (2017, November 21). The Most Common Conjunction | Synonym [Web log post]. Retrieved from http://classroom.synonym.com/commonconjunction-3317.html.
Kormos, J. Monitoring and Self-Repair in L2. Language Learning, 49(2), 1999: 303342. doi:10.1111/0023-8333.00090.

Kormos, J. The timing of self-repairs in second language speech production. Studies in Second Language Acquisition, 22(02), 2000: $\quad$ 145167.doi:10.1017/s0272263100002011.

Krashen, S.D. Principles and Practice in Second Language Acquisition. Oxford: Pergamon Press, 1982.

Leech, G. (1998). English grammar in conversation. Lancaster: Department of Linguistics and Modern English Language, 1998. Retrieved from: http://www. tuchemnitz. de/phil/ english/ chairs/ linguist/real/

independent/llc/Conference 1998/ Papers/ Leech/ Leech.htm.

Lintunen, P., \& Mäkilä, M. Measuring syntactic complexity in spoken and written learner language: comparing the incomparable? Research in Language, 12(4), 2014: 377-395. doi:10.1515/rela-2015-0005.

$\mathrm{Lu}$, Xiaofei. Automatic analysis of syntactic complexity in second language writing. International Journal of Corpus Linguistics, 15(4), 2010: 474-496.

Malvey, H. Persuasive language in high school students: differences in syntactic complexity in spoken and written language (Unpublished master's thesis). Texas Christian University, Fort Worth, TX, 2017.

Menn, L., \& Vilman, M. Features in child phonology: Inherent, emergent, or artefacts of analysis? In N. Clements \& R. Ridouane (eds.), Where Do Phonological Features Come From? The nature and sources of phonological primitives. Amsterdam: John Benjamins, 2011.

Nicolau, M. S., \& Sukamto, K. E. Gender differences in writing complex sentences: A case study of Indonesian EFL students. Indonesian Journal of English Language Teaching, 11(1), 2016: 69-80. 
Ohi, D. R. [comic strips], 2008. Retrieved from http://inkygirl.com/inkygirl-main/ tag/parents.

$\mathrm{Pu}, \mathrm{M}$. Spoken and written narratives: A comparative study. Journal of Chinese Language and Computing, 16(1), 2006: 3761.

Schegloff, E. A. Sequence Organization in Interaction: A Primer in Conversation Analysis 1. Cambridge: Cambridge University Press, 2007.

Silva, M. L., Sánchez Abchi, V., \& Borzone, A. Subordinated clauses usage and assessment of syntactic maturity: A comparison of oral and written retellings in beginning writers. Journal of Writing Research, 2(1), 2010: 47-64. doi:10.17239/jowr-2010.02.01.2.

Sukamto, K. E., \& Yanti. Self-repair in second language learner's speech. Paper presented at CONEST, Atma Jaya Catholic University of Indonesia, 2013, October.

Sun, Y., \& Yang, W. A Comparative analysis of discourse structures in EFL learners' oral and written narratives. International Journal of Linguistics, 3(1), 2011: 1-23. doi:10.5296/ijl.v3i1.917.

Tannen, D. (1993). What's in a frame? : Surface evidence for underlying expectations. In D. Tannen (ed.), Framing in discourse, 1993: 14-56. Oxford: Oxford University Press.

Tannen, D. Spoken and written narrative in English and Greek. In Deborah Tannen (ed.), Coherence in spoken and written discourse, 1984: 21-41. Norwood, NJ: Ablex.

Toolan, M. Narrative: A critical linguistic introduction. London: Routledge, 1988.

$\mathrm{Yu}, \mathrm{H}$. An exploratory study of narrative structures in Chinese tertiary EFL learners' monologic production. Beijing: Foreign Language Teaching and Research Press, 2005. 